\title{
Temporomandibular Disorder and Oral Health-Related Quality of Life in Brazilian Adults: A Population-Based Survey
}

\author{
Luísa R. A. Carvalho ${ }^{1}$, Aline A. Sampaio ${ }^{2}$, Fernanda L. Campos ${ }^{1}$, Gabriela A. C. Rhodes ${ }^{1}$, \\ Loliza L. F. H. Chalub ${ }^{1}$ \& Raquel Conceição Ferreira ${ }^{1}$ \\ ${ }^{1}$ Department of Social and Preventive Dentistry, School of Dentistry, Federal University of Minas Gerais, Belo \\ Horizonte, Brazil \\ ${ }^{2}$ Department of Clinic, Pathology and Dental Surgery, School of Dentistry, Federal University of Minas Gerais, \\ Belo Horizonte, Brazil \\ Correspondence: Aline A. Sampaio, School of Dentistry, Federal University of Minas Gerais, Belo Horizonte, \\ Minas Gerais, Av. Pres. Antônio Carlos, 6627 - Pampulha, Brazil. Tel: (31)-97-136-8116.
}

Received: January 11, 2021 Accepted: February 18, 2021 Online Published: March 9, 2021

doi:10.5539/gjhs.v13n4p95 URL: https://doi.org/10.5539/gjhs.v13n4p95

\begin{abstract}
Objective: Evaluate the association between TMD symptoms and physical and psychosocial oral health impact among adults of a small Brazilian municipality.

Methods: A population-based epidemiological study with a probabilistic sample of adults (30-49 years) was carried out. Data was collected in the participant's residence using a structured questionnaire, and a clinical examination was conducted by calibrated examiners (Kappa >0.7). The presence of TMD symptoms was evaluated using the Fonseca's Anamnesis Questionnaire (1994). Physical and psychosocial impact was considered if at least one oral functions item was reported as being experienced fairly often or very often, assessed by the Oral Health Impact Profile (OHIP-14), an instrument of Oral Health Related Quality of Life (OHRQoL). The association between TMD symptoms and presence of impact was adjusted for oral health condition, sociodemographic and socioeconomic profiles, and health behaviors. Associations were investigated using the crude and multivariate Poisson regression.
\end{abstract}

Results: Of the 197 participants, 114 (59.30\%) had physical and psychosocial impact of oral health and 135 $(68.19 \%)$ had at least one TMD symptom. After adjusting for covariates, individuals who reported TMD symptoms had a 1.75 times higher prevalence of impact $(95 \% \mathrm{CI} 1.18-2.57)$ than those who did not report symptoms, with psychological discomfort $(60.46 \%)$, physical pain $(40.19 \%)$, and psychological disability $(35.71 \%)$ being the most affected dimensions ( $p<0.01)$.

Conclusion: TMD is a common condition and the presence of symptoms is associated with impact in different dimensions of OHRQoL. These results demonstrate the importance of early identification of TMD symptoms to reduce the impact on OHRQoL.

Keywords: adults, epidemiology, oral health, health related quality of life, prevalence, temporomandibular disorders

\section{Introduction}

Temporomandibular disorder (TMD) is defined as a set of painful and/or dysfunctional conditions that affect the stomatognathic system, including masticatory muscles, the temporomandibular joint (TMJ), and associated structures, and is related to complex biopsychosocial factors (American Society of Temporomandibular Joint Surgeons [ASTJS], 2003; Durham et al., 2011). Pain is the most common symptom of TMD and can occur in the face, TMJ, masticatory muscles, mandible, maxilla, pre or post-auricular regions, ear, and the head. Pain may be exacerbated by chewing or other mandibular activity. Other reported symptoms are ear manifestations such as tinnitus, ear fullness, and vertigo (ASTJS, 2003).

TMD symptoms are frequent, with prevalence ranging from 26.4\% to 89.8\% (Locker \& Slade, 1998; Duckro, Tait, Margolis, \& Deshields, 1990; Miettinen et al., 2017; Natu, Yap, Su, Ali, \& Ansari, 2018; Nomura et al., 2007; Oliveira et al., 2003; Paulino et al., 2018; Pedroni, De Oliveira, \& Guaratini, 2003; Tay, Yap, Wong, Tan, \& Allen, 2019). Most studies on the prevalence of TMD or its symptoms were conducted with convenience samples of 
students (Nomura et al., 2007; Paulino et al., 2018; Pedroni, et al., 2003; Tay et al., 2019; Rodrigues et al., 2012; Bonjardim, Lopes-Filho, Amado, Albuquerque, \& Gonçalves, 2009; de Oliveira, Dias, Contato, \& Berzin, 2006) and a few were population-based studies (Locker \& Slade, 1998; Duckro et al., 1990; Gonçalves, Fabbro, Campos, Bigal, \& Speciali, 2010; de Siqueira, Vilela, \& Florindo, 2015; Franco-Micheloni, Fernandes, Gonçalves, \& Camparis, 2015; Mello, Barbosa, Morais, Gomes, Vasconcelos, \& Caldas Júnior, 2014). In Brazil, a study with a representative sample has estimated a 39.2\% prevalence of TMD symptoms (Gonçalves et al., 2010).

TMD symptoms may result in oral function impairment and often affect oral health related quality of life (OHRQoL). The OHRQoL concept covers the psychosocial impact related to oral diseases, and it can be measured by specific instruments (Chaves, de Oliveira, \& Grossi, 2008). A previous systematic review concluded that subjective TMD symptoms are more closely related to OHRQoL than clinical findings, supporting the use of patient centered outcomes (Dahlström \& Carlsson, 2010). Recent studies that evaluated this association were carried out on convenience samples of students (Natu et al., 2018) and military personnel (Tay et al., 2019), or did not consider potential confounding factors in the analysis (Durham et al., 2011; Natu et al., 2018; Tay et al., 2019; Dahlström \& Carlsson, 2010; Lemos, Paulino, Forte, Beltrão, \& Batista, 2015).

Therefore, population-based research controlled for confounding factors on the association between TMD symptoms and OHRQoL are needed, especially considering the physical and psychosocial dimensions separately. Patient centered outcomes are based on communication with participants and their involvement in their own health care (Santana et al., 2015; Silveira, Maroco, Freire, Martins, \& Marcopito, 2014; Baiju, Varghese, \& Sivaram, 2017; Zucoloto, Maroco, \& Campos, 2016). Thus, this population-based study evaluated the association between TMD symptoms and the prevalence of physical and psychosocial oral health impact. The hypothesis was that the presence of TMD symptoms is associated with a higher prevalence of impact on OHRQoL.

\section{Methodology}

This was a cross-sectional study conducted in 2018 and 2019 with adults (30 to 49 years old) living in the urban area of Rio Acima, a municipality in the metropolitan region of Belo Horizonte, Minas Gerais, Brazil. The sample size was estimated by a formula based on previously observed parameters of oral conditions and their impact on daily activities using the Epi ${ }^{\text {TM }}$ 7.2.1.0 (Centers for Disease Control and Prevention, Atlanta, GA, USA). The required sample size was 192, considering a margin of error of $5.5 \%$, a confidence level of $95 \%$, and a design effect (deff) of 1.2. We used a single-stage probabilistic sampling by clusters (census sectors) using a proportion of the population from all city sectors. After the identification of the 13 urban sectors, the random selection of streets (primary sampling unit) was carried out. The number of streets in each sector was a proportion of the total number of streets in each census sector. All households on the selected streets were visited and all adults ( 30 to 49 years old) were invited to participate in the research. The total edentulous individuals; those who used a fixed orthodontic appliance; had cognitive or mental impairment; or any limitation that would obstruct the examination and interview, were excluded. Those who refused to participate or were not found after three attempts, were considered missing.

Data was collected by an interview and clinical examination in the participant's residence. Four teams of one examiner (dentist) and one annotator (dental student) were trained in $32 \mathrm{~h}$ of workshop about the theoretical and practical aspects of the analyzed oral conditions. Practical training was carried out following the recommendations of the World Health Organization (WHO) for surveys in oral health (WHO, 2013). Five rounds of calibrations were performed for dental conditions (presence of caries and tooth loss) using the in-lux method until the ideal kappa was reached (Pinto, Leal, Santos, \& Roncalli, 2018). The intra-examiner kappa value was greater than 0.8 and the inter-examiner kappa varied between 0.70 and 1.0. Clinical training for periodontal assessment was conducted by a Periodontics professor until reaching agreement between the examiners. Software installed on tablets was used to record and store the collected data eliminating the use of paper form and allowed data to be quickly exported for analysis. In this software, the questions for interviews and clinical examination indexes were pre-programmed with their answer options, avoiding typing errors and allowing the automatic generation of the database. This data collection software used offline forms allowing researchers to store a backup of their data on a tablet and upload it as soon as an Internet connection was available.

The dependent variable was the presence of oral health impact on the physical and psychosocial dimensions, assessed by the Brazilian validated version of the Oral Health Impact Profile (OHIP-14) (Oliveira \& Nadanovsky, 2005). Participants indicated how frequently (never, hardly ever, occasionally, fairly often, very often) they experienced each of the 14 problems in the questionnaire in the past six months, on the dimensions functional limitation, physical pain, psychological discomfort, physical disability, social disability, psychological disability, and handicap. The prevalence of impact was considered when the respondent indicated at least one problem as 
occurring "fairly often" or "very often".

The main independent variable was the presence of TMD symptoms, assessed by the Fonseca's Anamnesis Questionnaire (1994), a screening instrument developed in Brazil (Fonseca, Bonfate, Valle \& Freitas, 1994). The sum of the scores results in the Anamnesis Index, which classifies individuals as: without TMD ( $0-15$ points), and mild (20-45 points), moderate (from 50-65 points), and severe TMD (70-100 points). Considering the low frequency of individuals in the four categories and that TMD symptoms can be transient, self-limiting, and intermittent, both "yes" and "sometimes" responses were considered as a positive response to the presence of symptoms, as previously used in other studies (Bevilaqua-Grossi, Chaves, Oliveira, \& Monteiro-Pedro, 2011). For association analyses, participants were grouped into two categories: absence (without TMD) and presence (mild, moderate, and severe TMD).

The study was based on the theoretical model shown in Figure 1, controlling for potential confounding factors regarding oral health conditions, sociodemographic and socioeconomic characteristics, and health behaviors.
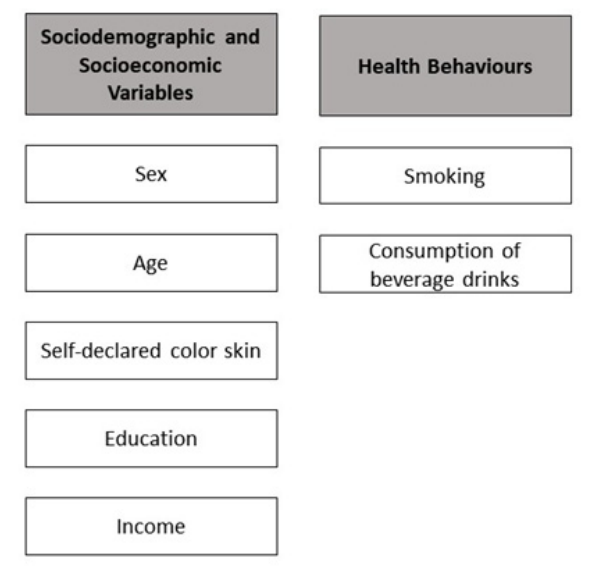

Smoking

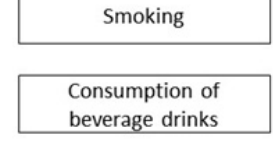

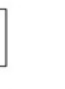

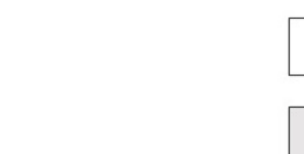

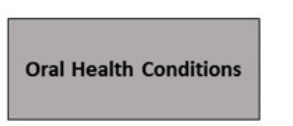
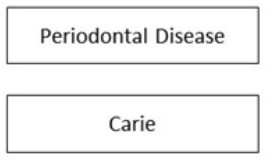

Tooth loss

Symptoms of Temporomandibular Disorders
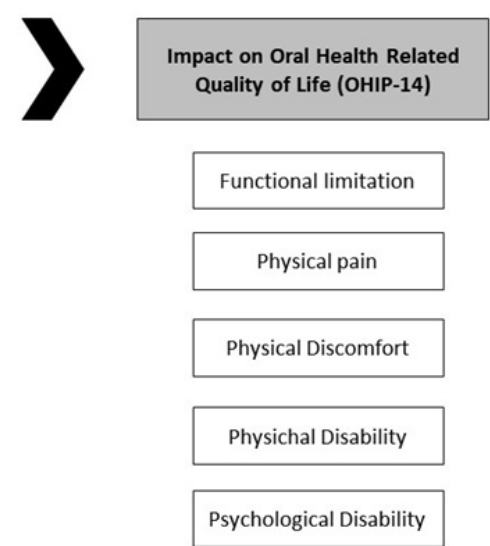

Social Disability

Figure 1. Theoretical model for investigating the association between temporomandibular disorder symptoms and the physical and psychosocial impact of oral conditions.

The periodontal condition, presence of caries, and reduced dentition were evaluated. Periodontal clinical parameters (probing depth (PD), clinical attachment level (CAL), and bleeding on probing (BP)) were assessed on the buccal, distal, mesial, and lingual or palatal surfaces of all teeth using a Williams millimeter-periodontal probe $\left(\right.$ Trinity $\left.^{\circledR}\right)$. The Classification of Periodontal and Peri-implant Diseases and Conditions (Caton et al., 2018) was used to classify participants as: healthy $(<10 \%$ of sites with BP, PD $<3 \mathrm{~mm}$, and absence of attachment loss), gingivitis (presence of $\mathrm{BP}$ in $>10 \%$ of the sites and absence of $\mathrm{PD}>4 \mathrm{~mm}$, regardless of the presence of attachment loss), or periodontitis (at least one site with PD $>4 \mathrm{~mm}$, with any attachment loss $>2$ in non-adjacent interproximal sites). The presence of dental caries was assessed according to WHO (2013) criteria for decayed and filled teeth and dichotomized into: $0=$ without caries and $1=1$ or more decayed tooth. The concept of functional dentition as defined by the global goals of oral health (Hobdell, Petersen, Clarkson, \& Johnson, 2003) was used for assessing reduced dentition, and the number of natural teeth were counted considering the criteria for healthy, decayed, filled with caries, filled with no caries, and fissure sealant.

Health behaviors included smoking and consumption of alcoholic beverages. Smoking was evaluated according to the WHO (2013) with the question "Do you have a habit of smoking or using tobacco?" to which the answers "( 0 ) no, never used tobacco", "(1) no, ex-smoker or ex-tobacco user for more than 5 years", "(2) no, ex-smoker or extobacco user for less than 5 years", and "(3) yes", were categorized as: non-smoker (0), ex-smoker (1 and 2), and smoker (3). Heavy alcohol consumption was evaluated using the AUDIT question (33): "How often do you have 6 or more drinks on one occasion?" The individuals were classified in three categories: not a heavy drinker ("never" has 6 or more drinks); sporadic heavy drinker (has 6 or more drinks less than once a month or monthly), and heavy 
drinker (has 6 or more drinks weekly or daily) (Lima et al., 2005).

The socioeconomic characteristics assessed were sex (male and female), age (collected in full years and categorized into age groups from 30 to 39 years and 40 to 49 years), self-declared skin color, education level, and monthly family income. Skin color was assessed according to the classification criteria of the Brazilian Institute of Geography and Statistics - IBGE - and grouped into whites and black, brown, yellow or indigenous (Oliveira \& Nadanovsky, 2005). Education was assessed using the questions "How many years did you study?" and "What is your education level?" with answer options ranging from "Never went to school (illiterate)" to "Postgraduate". The answers were converted into years of study according to the Brazilian school system and grouped into three categories: up to 4 years, from 5 to 8 years, and over 9 years of study. The monthly family income was assessed according to the methodology of the national epidemiological survey (WHO, 2013) and grouped into three categories: up to US\$387.00, from US\$387.00 to US\$645.00, and above US\$645.00.

Descriptive analyzes were first conducted. Then, the prevalence $(95 \% \mathrm{CI})$ of physical and psychosocial impact of oral conditions and symptoms of TMD were estimated, and the distribution of the impact according to TMD symptoms and covariates was calculated. The association between the independent variables and the presence of impact for each OHIP-14 dimension was assessed by a Poisson regression model with a crude and multivariate prevalence ratio estimate. Sample weights for each individual were calculated considering the probability of street draw and the non-response rate on each street. All analyses were performed with correction for the design effect and sample weight. Statistical analyses were performed using the SPSS ${ }^{\circledR} 17.0$ (SPSS Inc., Chicago, IL, USA) and Stata ${ }^{\circledR} 12.0$ (StataCorp, CollegeStation, Texas, USA) programs.

This study was approved by the National Council of Ethics in Research of the Federal University of Minas Gerais (CAAE 82540517.9.0000.5149).

\section{Results}

The respondents were 197 adults, with a mean age of 40.05 years (SE: 0.364, 39.32 - 40.78), mostly female (70.25\%), self-declared black, yellow, brown or indigenous (88.10\%), with an income below US\$387.00 (36.16\%), and nine or more years of study (52.54\%).

Physical and psychosocial impact of oral health was reported by 114 individuals (59.30\%). Of the 197 interviewed adults, only $12(6.45 \%)$ had no TMD symptom and $135(68.19 \%)$ had symptoms and scores $>20$ on the Anamnesis Index, being classified as mild TMD (41.51\%), moderate TMD (19.60\%), and severe TMD (7.08\%) (Figure 2).

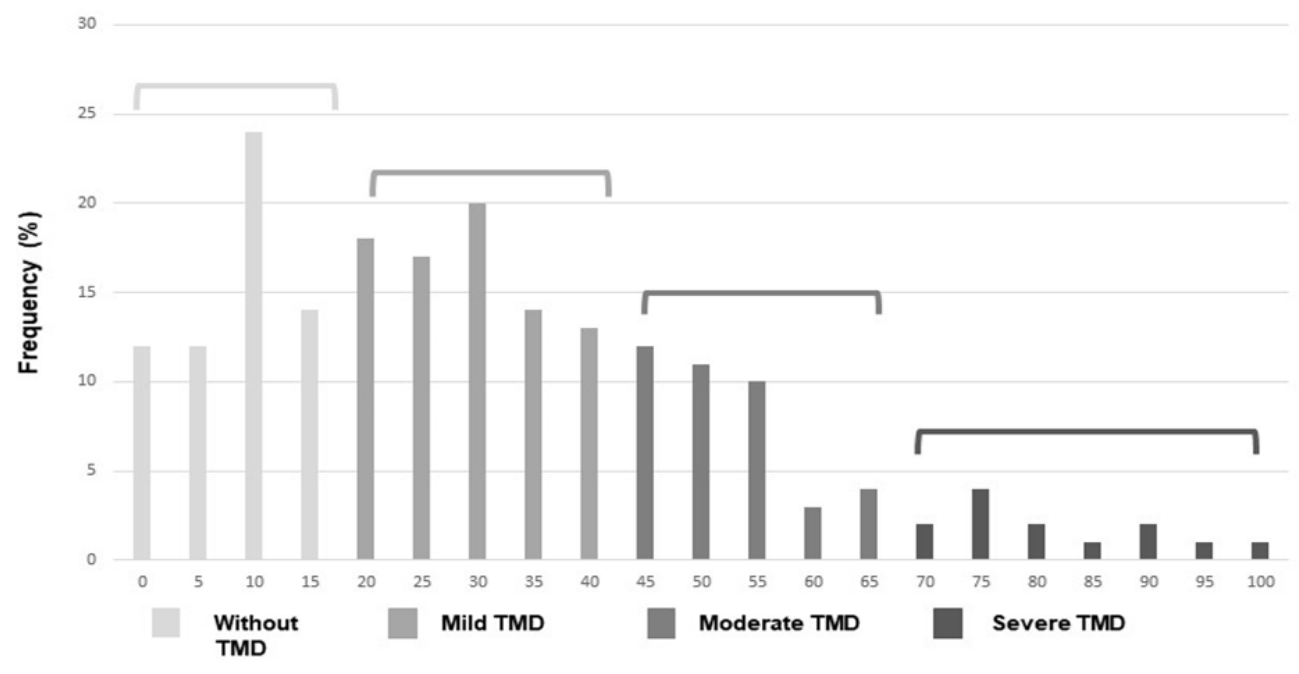

Figure 2. Distribution of adults according to the classification of the Anamnesis Index

In the bivariate analysis, individuals who reported TMD symptoms had a $2.05(1.33-3.18)$ times higher prevalence of impact compared to those without symptom (Table 1). 
Table 1. Crude analysis of the association between TMD symptoms and the presence of oral health-related physical and psychosocial impact and covariates referring to socioeconomic conditions, health behaviors, and oral health factors among adults in Rio Acima, MG, Brazil, in 2019

\begin{tabular}{lllc}
\hline VARIABLES & $\mathbf{n}(\%)$ & Presence of impact & Prevalence ratio (CI\%95) \\
\hline INDEPENDENT VARIABLE & & & \\
TMD Symptoms & & & \\
Absent & $83(40.70)$ & $22(34.47)$ & 1 \\
Present & $114(59.30)$ & $92(70.88)$ & $2.05(1.33-3.18)$ \\
\hline
\end{tabular}

\section{COVARIABLES}

Sociodemographic and socioeconomic characteristics

Sex

Male

$57(29.75) \quad 24(42.76)$

1

Female

$140(70.25) \quad 90(66.31)$

$1.55(1.17-2.05)$

\section{Age group}

30 to 39 years

$94(46.99) \quad 57(62.44)$

1

40 to 49 years

103 (53.01)

57 (56.52)

$0.90(0.70-1.16)$

\section{Self-declared skin color}

White

$23(11.90) \quad 13(59.71)$

1

Black + Yellow + Brown + Indigenous

$172(88.10) \quad 100(60.00)$

$1.00(0.68-1.47)$

\section{Education}

Up to 4 years of study

48 (28.03) $\quad 35(74.05)$

1

From 5 to 8 years of study

$37(19.43) \quad 26(68.72)$

$0.93(0.70-1.23)$

Over 9 years of study

$112(52.54) \quad 53(47.95)$

$0.65(0.48-0.87)$

\section{Monthly family income}

Up to US\$387.00

$67(36.16)$

$47(72.39)$

1

From US\$387.00 to US\$645.00

$64(34.03) \quad 29(46.67)$

$0.64(0.49-0.84)$

Above US\$645.00

$63(29.81) \quad 36(59.22)$

$0.80(0.64-0.99)$

\section{Health Behaviors}

Smoking

Non-smoker

137 (68.78)

77 (58.94)

1

Ex-smoker

35 (19.17)

$20(55.65)$

$0.94(0.67-1.33)$

Smoker

25 (12.05)

17 (67.15)

$1.14(0.78-1.66)$

\section{Consumption of alcoholic beverages}

No binge drinking

$116(57.81)$

$70(64.70)$

1

Sporadic heavy drinker

37 (17.94)

21 (57.98)

$0.90(0.63-1.27)$

Binge drinker

$44(24.25)$

23 (47.40)

$0.73(0.49-1.09)$

\section{Oral Health Conditions \\ Periodontal Disease}

Healthy

Gingivitis

Periodontitis

$\begin{array}{ll}62(30.33) & 35(59.04) \\ 15(7.51) & 7(45.84) \\ 120(62.16) & 72(61.05)\end{array}$

7 (45.84)
1

$0.78(0.49-1.24)$

$1.03(0.80-1.33)$ 


\section{Presence of caries}

Decayed component $=0$ $52(23.60)$ 22 (44.27)

At least one decayed tooth

145 (76.40)

$92(63.94)$

$1.44(1.01-2.06)$

\section{Reduced dentition}

$<21$ teeth

$\geq 21$ teeth

182 (92.77)

$$
103 \text { (58.01) }
$$

$0.76(0.56-1.04)$

The multiple regression model showed an association between TMD symptoms and the presence of impact regardless of covariates. Individuals who reported TMD symptoms had a 1.75 (CI 95\%: 1.19 - 2.57) times higher prevalence of impact than those without symptom. In the final model, the covariates that showed a significant association with the presence of oral health impact were: reduced dentition (having more than 21 teeth - protective effect) $(\mathrm{PR}=0.75 ; 95 \% \mathrm{CI}$ : $0.59-0.96)$, education (having more than 9 years of study - protective effect $)(\mathrm{PR}=$ 0.67 ; 95\% CI: 0.50-0.93), and sex (female) ( $\mathrm{PR}=1.48$; 95\% CI: 1.04-2.11) (Figure 3).

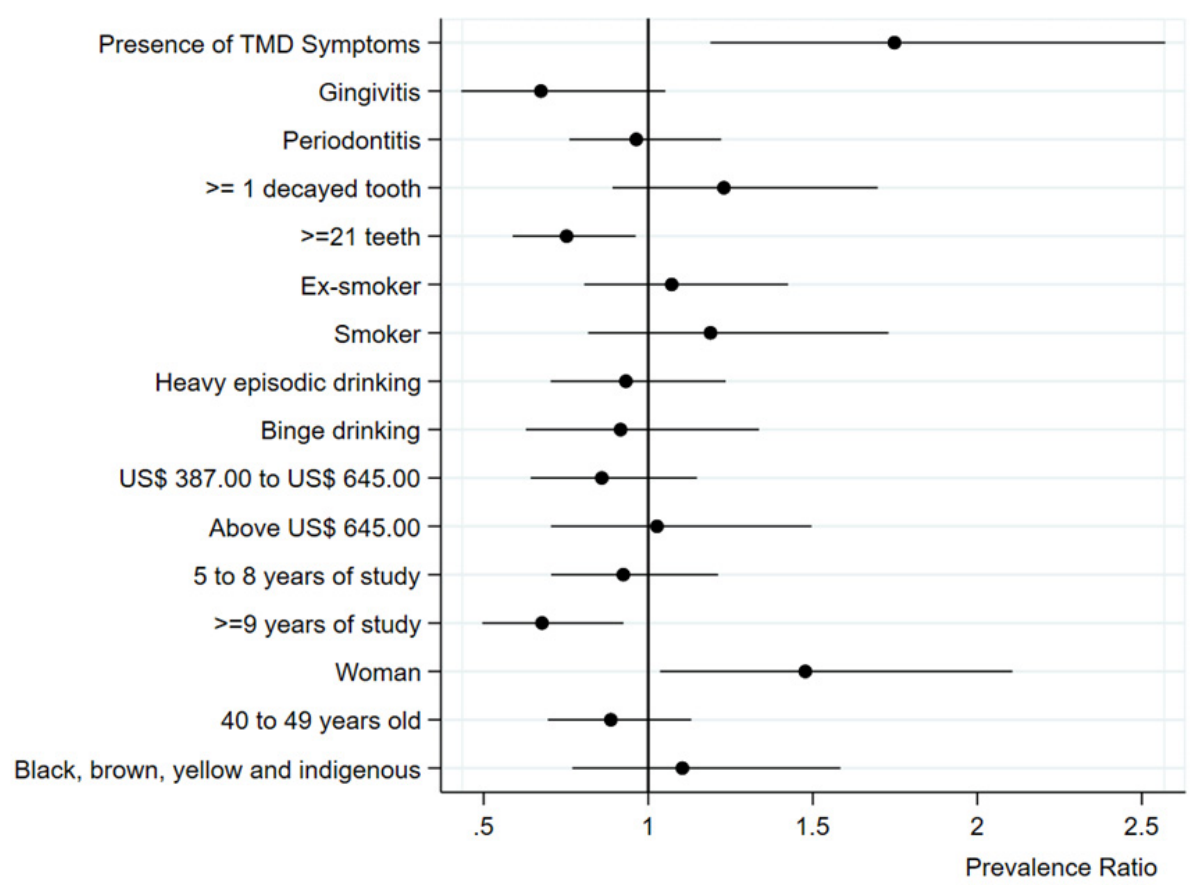

Figure 3. Prevalence ratio obtained in the multiple regression model of the association between TMD signs and symptoms and physical and psychosocial oral health impact among adults from Rio Acima, MG, Brazil, in 2019

The association between TMD symptoms and oral health impact was statistically significant for all dimensions of OHRQoL (Physical pain [PR: 2.0, 95\% CI: 1.20-4.15]; Psychological discomfort [PR: 2.06, 95\% CI: 1.28-3.31]; Physical disability [PR: 3.58, 95\% CI: 1.27-10.06]; Psychological Disability [PR: 6.27, 95\% CI: $1.98-19.80$ ]; Handicap [PR: 4.12, 95\% CI: 1.11-15.33]), except for the functional limitation dimension (PR: 3.04, 95\% CI: $0.54-17.04)$; with psychological discomfort $(60.46 \%)$, physical pain $(40.19 \%)$, and psychological disability (35.71\%) being the most affected dimensions in participants with TMD (Figure 4). 


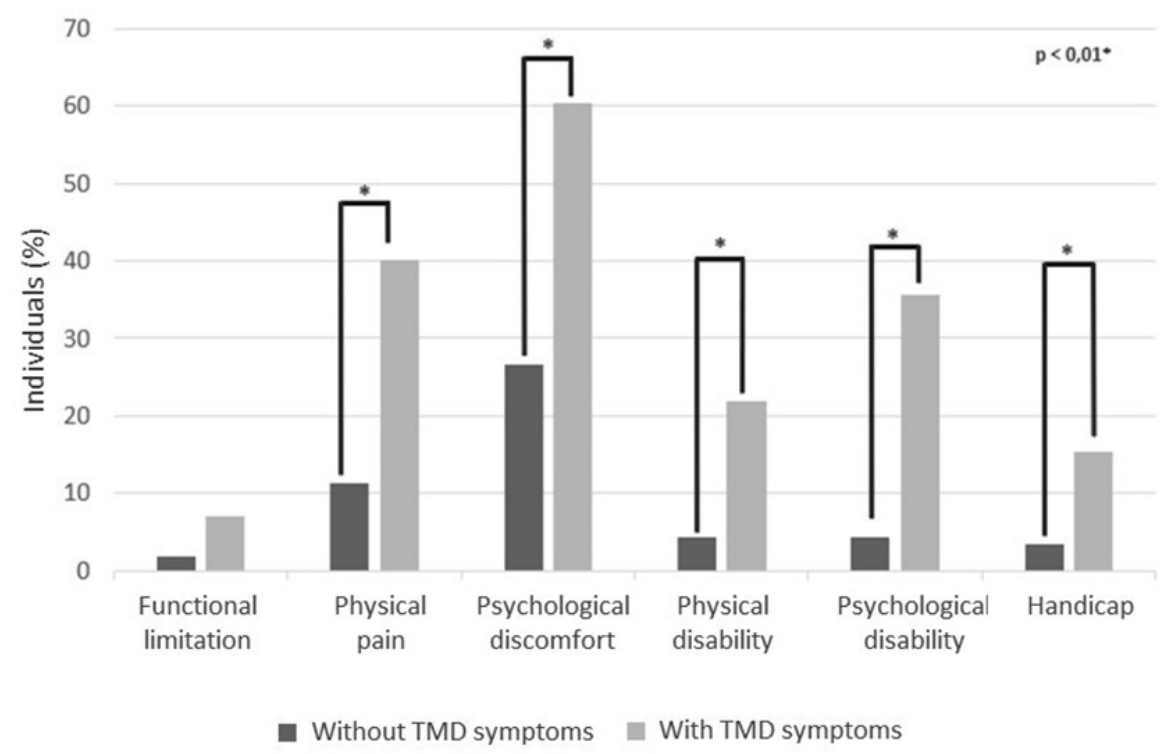

Figure 4. Oral health impact on Functional limitation, Physical pain, Psychological discomfort, Physical disability, Social disability, Psychological disability, and Handicap dimensions measured by the OHIP-14 according to the presence of symptoms of TMD among adults aged 30-49

Note: The regression model was not adjusted for the Social Disability dimension of OHIP, as there were no individuals with impact and without TMD symptoms in the sample. *Significant association adjusted for sex, age group, self-declared skin color, education, income, smoking, consumption of alcoholic beverages, periodontal disease, presence of caries, and reduced dentition.

\section{Discussion}

Adults who reported TMD symptoms had a higher prevalence of oral health impact on the physical and psychosocial dimensions, regardless of potential confounding factors. This finding shows that the presence of TMD symptoms can compromise oral function, manifested as discomfort in eating and chewing food, anxiety and stress, irritation, difficulty in relaxing, and impaired performance of daily tasks and work capability (Durham et al., 2011; Natu et al., 2018; Tay et al., 2019; Lemos et al., 2015).

The prevalence of TMD symptoms in our sample was higher than that observed in population studies in Canada (48.8\%) (Locker \& Slade, 1988), the United States (29.8\%) (Duckro et al., 1990), and Brazil (39.2\%) (Gonçalves et al., 2010). These previous studies were phone surveys among sample of adults and they used different questionnaires to assess the presence of symptoms. Duckro et al. and Locker \& Slade assessed presence of TMD symptoms using non validated questionnaire. The first one included five questions about TMD symptoms (grind teeth, sore of teeth, gums or jaw muscles when wake up, jaw sore or tired when chewing, talking or eating; jaw make popping or clicking sounds during chewing; clench or grind teeth in the daytime. The questionnaire also includes one question about frequency of severe headache and two questions about stress. In the study of Locker \& Slade, the individuals were asked about joint and facial pain, joint sounds, limitations in mandibular movement; locking, stiffness or tenderness bit. Those reporting one or more of these symptoms were asked further questions regarding their severity and functional consequences, frequent headaches, pain in the ears, neck, around the eyes. A validated five questions as recommended by American Academy of Orofacial Pain (AAOP) was used in Brazilian study (Gonçalves et al., 2010). The questions evaluated TMJ sounds and pain, masticatory muscle pain or fatigue of the jaw, difficulty during mouth opening and difficult during lateral deviation. Therefore, the absence of international standards and different assessment methods can explain the differences in prevalence among studies (Carrara, Conti, \& Barbosa, 2010).

The physical pain and physical disability dimensions were the most affected among those with TMD symptoms, which can be explained by the effect of TMD on chewing. TMD is a condition that can limit mandibular movements and cause muscle pain (Ferreira et al., 2018; Berni, Dibai-Filho, Pires, \& Rodrigues-Bigaton, 2015; Ferreira et al., 2014). Although a systematic review showed that the association between TMD and masticatory dysfunction is not well-established, 11 of the 17 studies included in the review showed a significant difference in 
masticatory function between groups with TMD symptoms and control groups (Ferreira et al., 2018). Thus, the findings of this epidemiological study indicate that TMD symptoms, such as pain, joint noises, changes or restrictions in mandibular movements, and limited mouth opening, can affect masticatory activity.

The association between presence of TMD symptoms and impact on discomfort and psychological dimensions is consistent with a previous study, which showed that greater dysfunction severity was related to higher scores on depression, anxiety and stress scales (Natu et al., 2018). Another study reported a significant association between psychosocial changes such as depression, somatization, and post-traumatic stress and TMD (Miller et al., 2019). A systematic review showed that psychosocial factors and psychological disorders are highly prevalent in patients with TMD symptoms (De La Torre Canales et al., 2018).

The OHIP-14 handicap dimension assesses the feeling that life in general is worse and the inability to perform daily activities due to oral problems. The observed association indicated that TMD symptoms may compromise daily activities. In fact, high-impact chronic pain in severe TMD was found to be disabling, reducing the quality of life and being associated with substantial restriction in professional, social, and self-care activities for six months or more (Miller et al., 2019).

TMD and its impact on physical and psychosocial aspects of life indicate the need for a patient-centered approach and an interprofessional action for diagnosis, prevention, and treatment. The scarcity of effective treatments and the likelihood of comorbidities, such as headache and other idiopathic pain conditions, result in a significant burden of disease. TMD is frequently associated with orofacial pain (OFP), and changes in the level of pain from low to high can result in increased direct health costs and indirect costs related to absenteeism and decreased productivity (Miller et al., 2019; Sociedade Brasileira de Disfunção Temporomandibular e Dor Orofacial, 2020). From a collective point of view, epidemiological data should guide the planning of TMD prevention, diagnosis, and control actions in the population, with a focus on improving people's quality of life. The International Association for the Study of Pain (IASP) proposes actions on public management, professional training, patient-centered approach, and production of scientific knowledge to respond to this frequent problem.

The associations observed in this study are in agreement with the literature, but they must be interpreted with caution due to the study design limitation, as the sample was not estimated to calculate associations, increasing the possibility of type II error. The Anamnesis Index was previously tested in Brazil, with an excellent correlation (95\%) with the Helkimo Index, a pioneer tool in the epidemiological investigation of TMD. However, the index can overestimate the presence of TMD symptoms, as it includes symptoms of headache, neck pain, and perception of emotional tension in the assessment, and these symptoms can occur due to causes other than TMD. ${ }^{19}$ Nevertheless, the Anamnesis Index is a useful screening tool for TMD symptoms and can raise the alert to the need for deeper diagnostic investigation. In addition, the exclusion of edentulous individuals may have underestimated the results, as they may present TMD symptoms. However, rigorous methodological procedures were used to maximize the validity of the findings, such as training of the team, use of validated instruments, and control of confounding factors. Generalization is restricted to the city of Rio Acima, but the results can be used as a reference for adults with a profile similar to the sample studied.

\section{Conclusion}

TMD is a common condition among adults and the presence of symptoms is associated with impact in the Physical pain, Psychological discomfort, Physical disability, Social disability, Psychological disability, and Handicap dimensions of OHRQoL. These results demonstrate the importance of early identification of TMD symptoms to prevention and control measures aiming to reduce the negative impact of this condition on people life.

\section{Acknowledgements}

This work was supported by FAPEMIG, Brazil (Fundação de Amparo à Pesquisa do Estado de Minas Gerais Programa Pesquisador Mineiro - PPM-00686-16 and PPM-00603-18); "Pró-reitoria de Pesquisa da Universidade Federal de Minas Gerais", Brazil; "Coordenação de Aperfeiçoamento de Pessoal de Nível Superior - Brasil (CAPES)" [001].

\section{Competing Interests Statement}

The authors declare that there are no competing or potential conflicts of interest.

\section{References}

American Society of Temporomandibular Joint Surgeons. (2003). Guidelines for diagnosis and management of disorders involving the temporomandibular joint and related musculoskeletal structures. Cranio, 21, 68-76. https://doi.org/10.1080/08869634.2003.11746234 
Baiju, R. M., Peter, E. L. B. E., Varghese, N. O., \& Sivaram, R. (2017). Oral health and quality of life: current concepts. Journal of clinical and diagnostic research: JCDR, 11(6), ZE21. https://doi.org/10.7860/JCDR/2017/25866.10110

Bevilaqua-Grossi, D., Chaves, T. C., De Oliveira, A. S., \& Monteiro-Pedro, V. (2006). Anamnestic index severity and signs and symptoms of TMD. CRANIO ${ }^{8}, 24(2), 112-118$. https://doi.org/10.1179/crn.2006.018

Bonjardim, L. R., Lopes-Filho, R. J., Amado, G., Albuquerque, R. L., \& Goncalves, S. R. (2009). Association between symptoms of temporomandibular disorders and gender, morphological occlusion, and psychological factors in a group of university students. Indian Journal of dental research, 20(2), 190. https://doi.org/10.4103/0970-9290.52901

Carrara, S. V., Conti, P. C. R., \& Barbosa, J. S. (2010). Termo do $1^{\circ}$ consenso em disfunção temporomandibular e dor orofacial. Dental Press Journal of Orthodontics, 15(3), 114-120. https://doi.org/10.1590/S2176-94512010000300014

Caton, J. G., Armitage, G., Berglundh, T., Chapple, I. L., Jepsen, S., Kornman, K. S., ... \& Tonetti, M. S. (2018). A new classification scheme for periodontal and peri-implant diseases and conditions-Introduction and key changes from the 1999 classification. https://doi.org/10.1111/jcpe.12935

Chaves, T. C., Oliveira, A. S. D., \& Grossi, D. B. (2008). Principais instrumentos para avaliação da disfunção temporomandibular, parte I: índices e questionários; uma contribuição para a prática clínica e de pesquisa. Fisioterapia e pesquisa, 15(1), 92-100. https://doi.org/10.1590/S1809-29502008000100015

da Silveira Pinto, R., Leal, D. L., Santos, J. S., \& Roncalli, A. G. (2018). Projeto SB Minas Gerais 2012: Pesquisa das condições de saúde bucal da população mineira-métodos e resultados principais. Arquivos em Odontologia, 54.

Dahlström, L., \& Carlsson, G. E. (2010). Temporomandibular disorders and oral health-related quality of life. A $\begin{array}{llll}\text { systematic } \quad \text { review. Acta Odontologica } & \text { Scandinavica, }\end{array}$ https://doi.org/10.3109/00016350903431118

de Godoi Gonçalves, D. A., Dal Fabbro, A. L., Campos, J. A. D. B., Bigal, M. E., \& Speciali, J. G. (2010). Symptoms of temporomandibular disorders in the population: an epidemiological study. Journal of orofacial pain, 24(3).

De La Torre Canales, G., Câmara-Souza, M. B., Muñoz Lora, V. R. M., Guarda-Nardini, L., Conti, P. C. R., Rodrigues Garcia, R. M., ... \& Manfredini, D. (2018). Prevalence of psychosocial impairment in temporomandibular disorder patients: A systematic review. Journal of oral rehabilitation, 45(11), 881-889. https://doi.org/10.1111/joor.12685

de Oliveira, B. H., \& Nadanovsky, P. (2005). Psychometric properties of the Brazilian version of the Oral Health Impact Profile-short form. Community dentistry and oral epidemiology, 33(4), 307-314. https://doi.org/10.1111/j.1600-0528.2005.00225.x

de Siqueira, S. R. D., Vilela, T. T., \& Florindo, A. A. (2015). Prevalence of headache and orofacial pain in adults and elders in a B razilian community: an epidemiological study. Gerodontology, 32(2), 123-131. https://doi.org/10.1111/ger.12063

dos Santos Berni, K. C., Dibai-Filho, A. V., Pires, P. F., \& Rodrigues-Bigaton, D. (2015). Accuracy of the surface electromyography RMS processing for the diagnosis of myogenous temporomandibular disorder. Journal of Electromyography and Kinesiology, 25(4), 596-602. https://doi.org/10.1016/j.jelekin.2015.05.004

Duckro, P. N., Tait, R. C., Margolis, R. B., \& Deshields, T. L. (1990). Prevalence of temporomandibular symptoms in a large United States metropolitan area. CRANIO ${ }^{\circledR}, \quad 8(2), \quad 131-138$. https://doi.org/10.1080/08869634.1990.11678307

Durham, J., Steele, J. G., Wassell, R. W., Exley, C., Meechan, J. G., Allen, P. F., \& Moufti, M. A. (2011). Creating a patient-based condition-specific outcome measure for Temporomandibular disorders (TMDs): Oral health impact profile for TMDs (OHIP-TMDs). Journal of oral rehabilitation, 38(12), 871-883. https://doi.org/10.1111/j.1365-2842.2011.02233.x

Ferreira, C. L. P., Machado, B. C. Z., Borges, C. G. P., Da Silva, M. A. M. R., Sforza, C., \& De Felício, C. M. (2014). Impaired orofacial motor functions on chronic temporomandibular disorders. Journal of Electromyography and Kinesiology, 24(4), 565-571. https://doi.org/10.1016/j.jelekin.2014.04.005

Ferreira, M. C., Porto de Toledo, I., Dutra, K. L., Stefani, F. M., Porporatti, A. L., Flores-Mir, C., \& De Luca Canto, 
G. (2018). Association between chewing dysfunctions and temporomandibular disorders: A systematic review. Journal of oral rehabilitation, 45(10), 819-835. https://doi.org/10.1111/joor.12681

Fonseca, D. M., Bonfate, G., Valle, A. L., \& Freitas, S. F. T. (1994). Diagnóstico pela anamnese da disfunção craniomandibular. Revista Gaucha de Odontologia, 42(1), 23-28.

Franco-Micheloni, A. L., Fernandes, G., Aparecida de Godoi Gonçalves, D., \& Camparis, C. M. (2015). Temporomandibular Disorders in a Young Adolescent Brazilian Population: Epidemiologic Characterization and Associated Factors. Journal of Oral \& Facial Pain \& Headache, 29(3). https://doi.org/10.11607/ofph.1262

Hobdell, M., Clarkson, J., Petersen, P. E., \& Johnson, N. (2003). Global goals for oral health 2020. International dental journal, 53(5), 285-288. https://doi.org/10.1111/j.1875-595X.2003.tb00761.x

Lemos, G. A., Paulino, M. R., Forte, F. D. S., Beltrão, R. T. S., \& Batista, A. U. D. (2015). Influence of temporomandibular disorder presence and severity on oral health-related quality of life. Revista Dor, 16(1), 10-14. https://doi.org/10.5935/1806-0013.20150003

Lima, C. T., Freire, A. C. C., Silva, A. P. B., Teixeira, R. M., Farrell, M., \& Prince, M. (2005). Concurrent and construct validity of the AUDIT in an urban Brazilian sample. Alcohol and Alcoholism, 40(6), 584-589. https://doi.org/10.1093/alcalc/agh202

Locker, D., \& Slade, G. (1988). Prevalence of symptoms associated with temporomandibular disorders in a Canadian population. Community dentistry and oral epidemiology, 16(5), 310-313. https://doi.org/10.1111/j.1600-0528.1988.tb01783.x

Mello, V. V. C. D., Barbosa, A. C. D. S., Morais, M. P. L. D. A., Gomes, S. G. F., Vasconcelos, M. M. V. B., \& Caldas Júnior, A. D. F. (2014). Temporomandibular disorders in a sample population of the Brazilian northeast. Brazilian dental journal, 25(5), 442-446. https://doi.org/10.1590/0103-6440201302250

Miettinen, O., Anttonen, V., Patinen, P., Päkkilä, J., Tjäderhane, L., \& Sipilä, K. (2017). Prevalence of Temporomandibular Disorder Symptoms and Their Association with Alcohol and Smoking Habits. Journal of Oral \& Facial Pain \& Headache, 31(1). https://doi.org/10.11607/ofph.1595

Miller, V. E., Poole, C., Golightly, Y., Barrett, D., Chen, D. G., Ohrbach, R., ... \& Slade, G. D. (2019). Characteristics associated with high-impact pain in people with temporomandibular disorder: a cross-sectional study. The Journal of Pain, 20(3), 288-300. https://doi.org/10.1016/j.jpain.2018.09.007

Natu, V. P., Yap, A. U. J., Su, M. H., Irfan Ali, N. M., \& Ansari, A. (2018). Temporomandibular disorder symptoms and their association with quality of life, emotional states and sleep quality in South-East Asian youths. Journal of oral rehabilitation, 45(10), 756-763. https://doi.org/10.1111/joor.12692

Nomura, K., Vitti, M., Oliveira, A. S. D., Chaves, T. C., Semprini, M., Siéssere, S., ... \& Regalo, S. C. H. (2007). Use of the Fonseca's questionnaire to assess the prevalence and severity of temporomandibular disorders in Brazilian dental undergraduates. Brazilian dental journal, 18(2), 163-167. https://doi.org/10.1590/S0103-64402007000200015

Oliveira, A. S. D., Bermudez, C. C., Souza, R. A. D., Souza, C. M. F., Dias, E. M., Castro, C. E. D. S., \& Bérzin, F. (2003). Impacto da dor na vida de portadores de disfunção temporomandibular. Journal of Applied Oral Science, 11(2), 138-143. https://doi.org/10.1590/S1678-77572003000200010

Oliveira, A. S. D., Dias, E. M., Contato, R. G., \& Berzin, F. (2006). Prevalence study of signs and symptoms of temporomandibular disorder in Brazilian college students. Brazilian oral research, 20(1), 3-7. https://doi.org/10.1590/S1806-83242006000100002

Paulino, M. R., Moreira, V. G., Lemos, G. A., Silva, P. L. P. D., Bonan, P. R. F., \& Batista, A. U. D. (2018). Prevalence of signs and symptoms of temporomandibular disorders in college preparatory students: associations with emotional factors, parafunctional habits, and impact on quality of life. Ciencia \& saude coletiva, 23, 173-186. https://doi.org/10.1590/1413-81232018231.18952015

Pedroni, C. R., De Oliveira, A. S., \& Guaratini, M. I. (2003). Prevalence study of signs and symptoms of temporomandibular disorders in university students. Journal of oral rehabilitation, 30(3), 283-289. https://doi.org/10.1046/j.1365-2842.2003.01010.x

Rodrigues, J. H., Biasotto-Gonzalez, D. A., Bussadori, S. K., Mesquita-Ferrari, R. A., Fernandes, K. P. S., Tenis, C. A., \& Martins, M. D. (2012). Signs and symptoms of temporomandibular disorders and their impact on psychosocial status in non-patient university student's population. Physiotherapy Research International, 
17(1), 21-28. https://doi.org/10.1002/pri.508

Santana, M. J., Haverman, L., Absolom, K., Takeuchi, E., Feeny, D., Grootenhuis, M., \& Velikova, G. (2015). Training clinicians in how to use patient-reported outcome measures in routine clinical practice. Quality of Life Research, 24(7), 1707-1718. https://doi.org/10.1007/s11136-014-0903-5

Silveira, M. F., Marôco, J. P., Freire, R. S., de Barros Lima, A. M. E., \& Marcopito, L. F. (2014). Impacto da saúde bucal nas dimensões física e psicossocial: uma análise através da modelagem com equações estruturais Impact of oral health on the physical and psychosocial dimensions: an analysis using. Cad. Saúde Pública, 30(6), 1-15. https://doi.org/10.1590/0102-311X00072013

Sociedade Brasileira de Disfunção Temporomandibular e Dor Orofacial [sbdof.com.br]. Projeto de implantação do atendimento de pacientes com DTM e DO pela rede pública de saúde [acesso em 02 maio 2020]. Retrieved from https://dtmedor.wordpress.com/a-sbdof/saude-publica/

Tay, K. J., Yap, A. U. J., Wong, J. C. M., Tan, K. B. C., \& Allen, P. F. (2019). Associations between symptoms of temporomandibular disorders, quality of life and psychological states in Asian Military Personnel. Journal of oral rehabilitation, 46(4), 330-339. https://doi.org/10.1111/joor.12751

World Health Organization. (2013). Oral health surveys: basic methods (5th ed.). World Health Organization. Geneva.

Zucoloto, M. L., Maroco, J., \& Campos, J. A. D. B. (2016). Impact of oral health on health-related quality of life: a cross-sectional study. BMC Oral Health, 16(1), 1-6. https://doi.org/10.1186/s12903-016-0211-2

\section{Copyrights}

Copyright for this article is retained by the author(s), with first publication rights granted to the journal.

This is an open-access article distributed under the terms and conditions of the Creative Commons Attribution license (http://creativecommons.org/licenses/by/4.0/). 